\title{
Why you don't owe it to yourself to seek health
}

\author{
Samuel Gorovitz University of Maryland, Maryland, USA
}

\section{Author's abstract}

Sider and Clements provide a critical response to my view that there is no independent obligation to seek one's own health. They then argue that such an obligation exists. They are incorrect in their characterisation of my view; their critical discussion of the view they erroneously attribute to me is unconvincing; the positive argument they offer for their own view is unsatisfactory; they misjudge the significance of what is at issue; and they conclude by affirming a position that lacks a due regard for the rights of patients.

In Patients' Ethical Obligation for Their Health, Sider and Clements provide an apparently well-intentioned but ultimately dangerous amalgam of dubious arguments, unwarranted assertions, and misunderstandings. Their discussion includes a critical response to my view that there is no independent obligation to seek one's own health. They then argue that such an obligation exists. They are incorrect in their characterisation of my view; their critical discussion of the view they erroneously attribute to me is unconvincing; the positive argument they offer for their own view is unsatisfactory; and they seem to me confused in their judgement of the significance of what is at issue.

The authors seek to establish the thesis that 'an ethical obligation for health is a fundamental constituent of human morality, that we owe our health to ourselves as well as to others'. This point is presumably important in establishing the conclusion that physicians and their patients are 'engaged in a common moral enterprise which legitimately claims the allegiance of both parties'. But that thesis, which they fail to sustain, is not needed to support such a conclusion. Worse, they put the thesis to a quite different use in the end - a use, I shall argue, which is at odds with the requirements of a moral enterprise.

It is hard to know what to make of their claim that medical ethics over the last two decades has been

\section{Key words}

Health; obligation; ethics; empiricism; rationalism; individuals; autonomy; connectedness; values; judgement; expertise. dominated by a rationalist approach. Sider and Clements use the terms 'rationalist' and 'naturalistic' in ${ }^{\Phi}$ a philosophically idiosyncratic way, rather than to $\overrightarrow{0}$ invoke the epistemological categories traditionally designated by those terms. To set the matter straight, $\overrightarrow{\vec{\omega}}$ I use 'rationalist' to refer to the views of Kant, and to ${ }_{0}$ those writing in his tradition, who do not see ethics as a fundamentally empirical subject. The contrast $\vec{x})$ typically, is with the empiricists, who, with Mill and

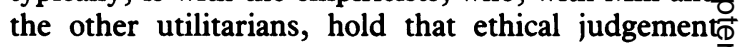
depends ineliminably on matters of fact.

If there has been a dominant tone in medical ethics over the last two decades - a dubious claim, at best - it $\vec{c}$ would surely be as a result of the prominence $\frac{\Phi f \circ}{\infty}$ utilitarian thought, paradigmatic of the no rationalist, empiricist approach to ethics. Odd Kant, the paradigmatic rationalist, is the writer mosts prominently associated with the view that Sider ando Clements seek to support: that one has an obligation too oneself to seek and maintain health. Thus, they attack $\varrho$ my typically empiricist position as being rationalistic $\overrightarrow{\overrightarrow{0}}$ and then argue for a typically rationalist position with a (flawed) empirical argument!

Space will not permit a thorough review of this complex discussion; I will simply touch the highlights, focusing first on their criticism of my position, and then on my criticism of theirs.

Sider and Clements seem confused in their critica discussion of the view that each person 'stands alone aso the creator of his values and purposes'. That is true, but it does not follow, as they claim it does 'that each? patient is prima facie free to regard his or her own health with whatever degree of value or disvalue he or she sees fit'. The values we choose are fundamentally o $^{\circ}$ interpersonal. We do not live in isolation; our structures of knowledge, our character, our personalities are all fundamentally social. It is not $\omega$ merely that the lives we lead are typically intertwinece with the lives of others; it is that what and who we are is a product of that connectedness with oures backgrounds and our interpersonal environments. It is in this contect that we choose our values, and it is thiscontext which, as a matter of empirical fact, typically makes it morally incumbent upon us to show regard for our health. 
The authors claim that my 'conception of medical ethics has great difficulty grounding a moral obligation for health. . . . in a rationalist scheme, there is no obligation to oneself to be healthy'. But this is no argument at all. I do not want to ground an obligation to oneself to be healthy, because there is no such obligation - which was a part of my point. But I have no trouble at all grounding a moral obligation for health:

'It would be hard to argue convincingly that one literally owes it to oneself to be protective of one's health. . . . But most owe it to others, for a variety of reasons, to seek and maintain good health. Those who lack any such obligation are free to abandon their health and even their lives without thereby violating a moral obligation. But that freedom exists only in consequence of the chilling impoverishment of their lives (1)'.

It is for this reason, combined with the fact that patients typically do want to promote their health, that I see patients and physicians as typically engaged in a common moral enterprise which legitimately claims the allegiance of both parties - precisely what Sider and Clements want to establish. Why, then, are they so discontent with my views?

They go on to claim that 'Without a purposive moral order extending beyond individual choice and contractual obligation, doctors' belief that responsibility for health is inherently a moral demand can only be dismissed as self-serving'. This doubly odd remark reveals much. First, it is a clue, albeit a gentle one, that Sider and Clements are engaged in an undertaking the purpose of which is primarily protective of physicians and their prerogatives. Why must such a belief be dismissed as self-serving, rather than as an understandable confusion? Physicians are bred to a respect for health; their patients typically enter into relationships with them in quest of health. It is natural for physicians to see responsibility for health as a moral demand - a demand they can reasonably be seen as affirming because of their desire to serve their patients, rather than themselves. One wonders here why it is so crucial to Sider and Clements that physicians be correct in that perception.

Second, the remark reveals that Sider and Clements are seeking to establish a universal and exceptionless obligation. Why else would it matter that the obligation for health be an inherently moral demand? Why else would it be insufficient that most people, most of the time, have a moral obligation to show regard for their health?

Astonishingly, Sider and Clements say, referring to an obligation for health that is grounded on membership in the human community, that my 'failure to discern such an obligation follows from his prior philosophical commitment to the idea that moral obligations must be necessary, immutable and universal'. They cite no evidence for such a prior commitment, nor could they; my discussion makes it plain to any careful reader that I take precisely the opposite view. It is, rather, the inherent moral demand' that Sider and Clements seek that is 'necessary, immutable and universal'. Ironically, they proceed to appeal to 'the real world of contingent imperatives' to argue for the reality of an independent obligation for health; it is in precisely that world that my own non-rationalist, empiricist case for healthrelated obligations finds its justification.

I shall return to this question of the universality of the obligation for health when I argue that Sider and Clements are themselves engaged in a physicianserving endeavour. First, I want to examine some of their positive arguments.

They claim, rightly, that ethics must not be purely procedural, but must have substantive content. The prevailing views in medical ethics, evident throughout the vast contemporary philosophical literature on the subject - of both rationalist and empiricist persuasions - hold that the substantive content of ethics includes such values as the moral equality of all persons, respect for the interests and autonomy of each, faithfulness to others, and the like. I do not understand how Clements and Sider can possibly see contemporary moral thought as free of content.

They proceed to offer a puzzling attempt to ground ethics in a few commonplace evolutionary observations. Granted that species survival is a value, and that health is fundamental to the achievement of long-term species goals, it remains a mystery how ethics is supposed to arise out of all that. Why should any post-reproductive individual be moved by considerations of health? Why should 'minimum healthy function' be accepted as an adequate standard for serious discussions about the obligations in regard to health in any event? In the contingent world in which I live, debates about responsibility for health do not focus primarily on questions of survival and reproduction; they often focus on something rather more like the Socratic notion of health as ideal functional capacity.

Sider and Clements claim that no obligations can be established unless it can be shown that there is an obligation to self. The aim of this non sequitur is to justify the physicians' feeling 'that the patient does have an obligation to function well biologically'. The argument that follows is essentially a case for ethics by statistical analysis. They write:

'Within an accurate description of how human beings either perceive or feel (whether using an intersubjective or population norms approach), we can say a particular individual falls outside the range of accurate perception or outside the range of functional human attitudes . . . such an individual . . . has failed in his obligation to himself.'

The point here is that what is judged to be generally good for people is obligatory for all people. And that judgement is to be made in a scientific, empirical way. 
What deviates from the functionally advantageous is not merely dysfunctional, imprudent, lamentable, or stupid, but constitutes a violation of obligation. We are not told how this last point is established, but let us accept it for the moment. A surprise promptly follows, for we are next told that 'Some individuals fall so far outside these population norms, that our intersubjective consensus would excuse their selfobligation'. Thus is ethics by statistics replaced with ethics by plebiscite!

Such exceptions are exemplified by certain among the terminally ill, those whose lives are intolerably and intractably distasteful, and others. Sider and Clements thus startlingly give up the game, by granting at a stroke precisely what their opponents have been arguing all along - that there is no inherent obligation for health; rather, the presence or absence of such an obligation depends on the individual circumstances. As a statistical point, most people are not among the exceptional cases, which is why it is reasonable to conclude that patients and physicians are typically engaged in a common enterprise that is not merely mutually convenient, but has moral content as well.

The moral content depends on the networks of contingent obligations that bind the patients and physicians. I fail to see how Sider and Clements have given any account of the origin of their 'selfobligation'. They simply assert that most people would agree that the obligation does not apply in cases sufficiently extreme. My own view, in contrast, by grounding obligations in networks of human aspirations and relationships, can account for why the obligations are present or lacking in each case.

In a further effort to make their position credible, the authors note that:

'The patient who continues to lacerate wrists, the selfstarving anorexic, the three-pack a day smoker, the non-compliant diabetic, the fearful or denying patient who refuses surgery - while not common, are also not individuals held up as examples of "the good man".'

And rightly not, for they exhibit severe imprudence, and typically violate their obligations to others in doing so. They are not admirable, but the examples lend no support to Sider and Clements - who seem simply not to appreciate the variety of ways in which behaviour can fail to merit admiration.

In their penultimate section, the authors address the notion of health as an obligation to others. Here, they observe that when we bond with others, we become ethically responsible to regard their feelings in choosing our health-related behaviours. They claim of rationalist ethics (and I can only presume they are still referring to my views this way) that it cannot satisfactorily articulate these ethical obligations. In the absence of a verbal promise or contract, rationalism struggles to find a basis for moral claims.' They seem here to be offering back to me as their own that part of my previous argument that they chose to ignore:
'Obligations can arise from promises, contracts, $\stackrel{2}{\propto}$ agreements, and even implicit understandings ... W Certain special relationships involve the undertaking $\overrightarrow{\bar{\circ}}$. of special obligations, such as those incurred in? marriage, which bind the participants to each other in $\vec{F}$ certain legally specified ways. But beyond these $e^{\text {f }}$ specified obligations there exist further obligations? implicit in that special relationship. . . . to enter into a marriage . . . is to undertake voluntarily to pursue and $\frac{\text { }}{\Phi}$

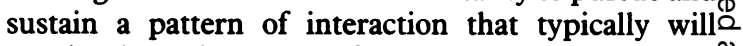
require the maintenance of one's health (2)'.

Sider and Clements go on, importantly, to explain that 'these commitments are not always chosen, but rather $\vec{\omega}$ are our lot as human beings, born into families, cultures and the species'. This I welcome as $a_{\Phi}$ significant addition, wholly in the spirit of what I have $-\frac{-}{\circ}$ written, but going beyond it.

I agree that obligations can arise out of our being $\vec{A}$ born into, and functioning in the context of, social $\omega$ institutions such as family and community. Similarly, 을 the patient, simply by functioning in the context of health care, has certain obligations - such as to regard $d_{\mathbb{D}}$ the feelings and interests of health-care providers, and웅 not to place demands on the resources of others by self- $-\frac{\mathbb{D}}{3}$ indulgently disregarding health needs and then claiming entitlement to costly care.

But these obligations are neither inherent nor alwass $\vec{\infty}$ overriding. They can come into conflict with ot values, which sometimes can dominate. That is whto happens in the case of the hopelessly ill and suffering patient who would rather see family resourcespreserved for the sake of others than have them depleted for the sake of a modest extension of a failing $\mathscr{Q}$ and distasteful existence. Such a person should not be $\overrightarrow{\vec{\Omega}}$ indifferent to the wishes of the health-care providers, $\frac{3}{3}$ but need not be dominated by them. It is precisely in these arguable cases around the borders of normato experience that judgement is required - sensitive, humane, open-minded judgement. As Sider and Clements themselves point out, there are cases soo deviant from the norm that there is consensus that the. typical value judgements do not apply to them. Buto there are also cases much less clear, about which argument can reasonably proceed. How ought those cases to be decided? Here is where the paper by Sider $>$ and Clements takes its dangerous turn.

There is no doubt that the trends of opinion in medical ethics over the last two decades have been ${ }^{\circ}$ strongly in favour of increased participation by $\tilde{O}^{\circ}$ patients and family members in the making of vitat health-care decisions. Since physicians are noto typically trained to share authority, for many of themo this trend has made the practice of medicine even more् difficult than it would otherwise be. Their lives would? be simpler, to be sure, if they could return to the goodo old days in which the maxim 'Doctor knows best' was? an argument-stopper. Sider and Clements weave circuitous path, but its terminus is worrisome. They $\frac{\mathbb{P}}{2}$ conclude with a flourish: 
'Patients are free, of course, except when in extremis, to disregard their doctors' advice. But in doing so, they risk violating fundamental ethical obligations and invite justifiable disapproval.'

Is this not 'Doctor knows best' with a new twist? No longer is the patient merely imprudent who violates the authority's dicta; now, the patient is in moral peril, as well.

We've had, I think, quite enough of that sort of attitude, and contemporary medical ethics has been a welcome antidote to it. Of course physicians know best about many matters, and their advice ought often to be heeded. But it is precisely in cases at the margins, where clashes of value are intertwined with the medical realities, that the physician's expertise runs out. There, the physician's views deserve a hearing as the views of one of the principal players, but they do not have any special status as the voice of authority. Consequently, although it may be immoral for a patient to violate a physician's advice in such circumstances, it will not be immoral simply because it is the violation of such advice, and it may not be immoral at all. It takes an independent argument to show that moral obligations in the particular circumstances commit the patient to the behaviour urged by the physician.

In typical interactions between physicians and patients, there is shared responsibility, and the patient who is negligent in regard to it violates obligations of many sorts. But there is no need to hypothesise any inherent or universal obligation, nor any obligation to oneself, to account for that. Had Sider and Clements succeeded in establishing an obligation of such pervasiveness, its very generality would protect physicians against the need to make distinctions, to stay on the alert for the rare exceptions in which the presumptive value of health is overridden by tragic circumstances. I can understand why they might welcome that simplification of the physicians' burdens, but I see no reason to concede it to them. And since they acknowledge the reality of such exceptions, it is a mystery what they believe they have gained by their argument.

They would do better to acknowledge that in a fundamentally moral enterprise like the practice of medicine, in which complex networks of aspirations and obligations can further cloud an already difficult context of decision, there is no more reason to apply sweeping generalisations about ethics than about the medical realities. Both commonly depend on subtle discriminations about the case at hand. The rationalists, like Kant, may seek comfort in the constancy of immutable rules, but we empiricists know better.

\section{References}

(1) Gorovitz S. Doctors' dilemmas: moral conflict and medical care. New York: Macmillan, 1982: 60.

(2) See reference (1): 56-58. 